\title{
Value of 3D-TOF MR angiography and 4D-dynamic contrast-enhanced MRI in the assessment of spontaneous posterior cavernous sinus dural arteriovenous fistula
}

Valor da angiografia por ressonância magnética 3D-TOF e RM 4D-dinâmica pós-contraste na avaliação de fístula arteriovenosa espontânea do seio cavernoso

Francisco Bermal CAPARROZ NETO', Lucas Giansante ABUD'1,2, Rafael Gouveia Gomes de OLIVEIRA², Daniel Giansante $A B \cup D^{3}$, Soraia Ramos Cabete $F A B I O^{4}$

A 46-year-old female patient presented symptoms of complete right oculomotor nerve palsy without proptosis. Orbital magnetic resonance (MR) imaging showed no abnormalities (Figure1). 3D time-of-flight MR angiography revealed high signal intensity in the right cavernous sinus (Figure 2). This isolated finding has a $10-15 \%$ rate of false-positive in the diagnosis of dural arteriovenous fistula $(\mathrm{DAVF})^{1}$. Additional 4D-dynamic contrast-enhanced MR angiography evidenced an early asymmetric enhancement of bilateral cavernous sinus, mainly on the right, draining downward through the inferior petrous sinus (Figure 3$)^{2,3,4,5}$.
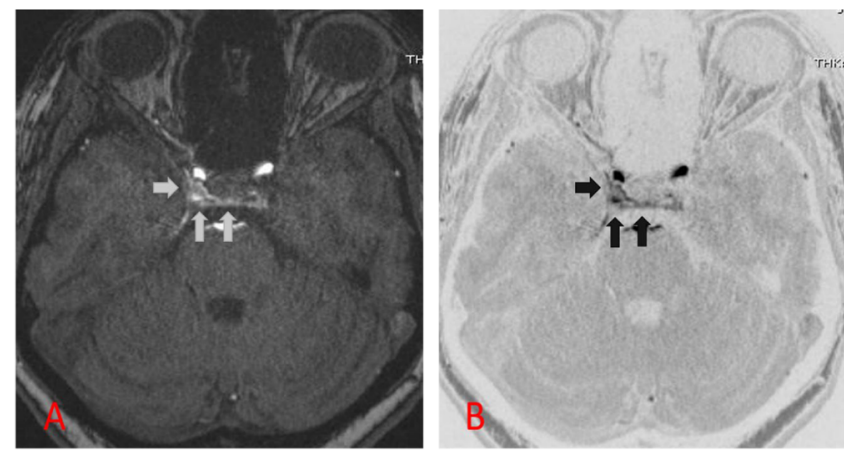

Figure 2. 3D time-of-flight MR angiography $(A)$ and the inverted window of this sequence (B) showed a subtle enlargement of the right cavernous sinus and parasellar high signals (arrowhead).
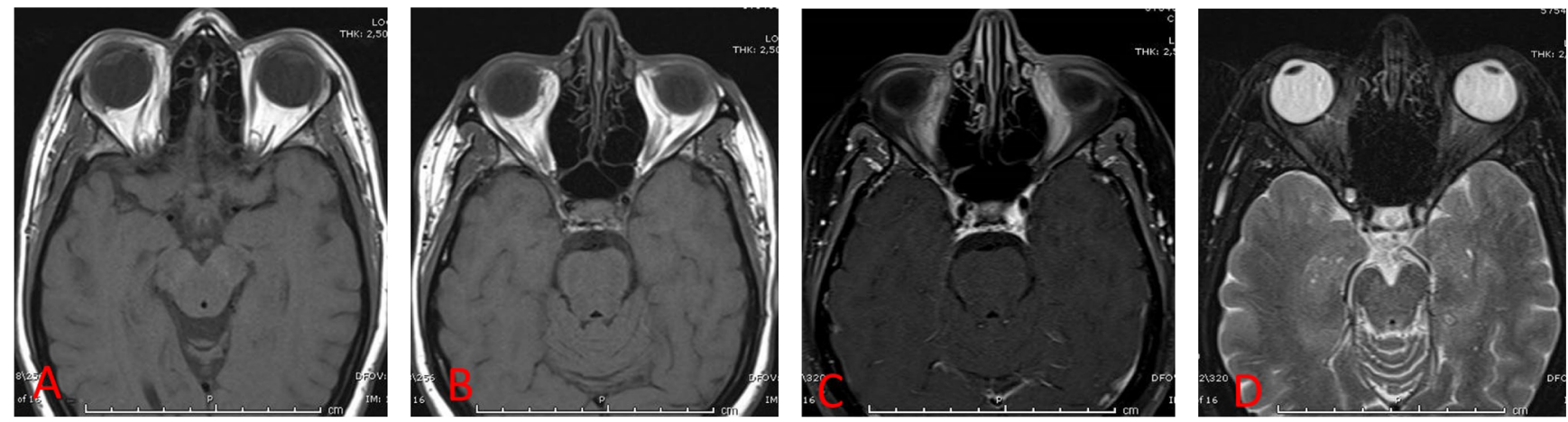

Figure 1. T1-weighted spin-eco (A and B), T2-weighted fat-saturated (A), and post-contrast T1-weighted (B) images from the orbital MR imaging showed no abnormalities. Of note, there are no signs of ocular proptosis or superior ophthalmic vein dilatation.

\footnotetext{
1Documenta, Hospital São Francisco, Departamento de Radiologia e Diagnóstico por Imagem, Ribeirão Preto SP, Brazil.

${ }^{2}$ MED Medicina Diagnóstica, Hospital São Lucas, Departamento de Radiologia e Diagnóstico por Imagem, Ribeirão Preto SP, Brazil.

${ }^{3}$ Universidade de São Paulo, Faculdade de Medicina de Ribeirão Preto, Divisão de Neurorradiologia Intervencionista, Ribeirão Preto SP, Brazil.

${ }^{4}$ Hospital da Unimed de Ribeirão Preto, Departamento de Neurologia, Ribeirão Preto SP, Brazil.

Francisco Bermal CAPARROZ NETO (iD https://orcid.org/0000-0003-0806-3279; Lucas Giansante ABUD (iD) https://orcid.org/0000-0002-3777-5753;

Rafael Gouveia Gomes de OLIVEIRA (iD https://orcid.org/0000-0002-3255-2710; Daniel Giansante ABUD (iD) https://orcid.org/0000-0002-6171-669X;

Soraia Ramos Cabete FABIO (iD) http://orcid.org/0000-0001-8481-7146
}

Correspondence: Francisco Bermal Caparroz Neto; E-mail: fbermal@hotmail.com

Conflict of interest: There is no conflict of interest to declare.

Authors' contributions: FBCN: conception, organization, writing of the first draft, review and critique; LAG, RGGO, SRCF: review and critique; DGA: execution, review and critique.

Received on September 08, 2020; Accepted on September 26, 2020 
Digital subtraction angiography confirmed a posterior cavernous sinus DAVF, and endovascular treatment was prescribed (Figure 4).
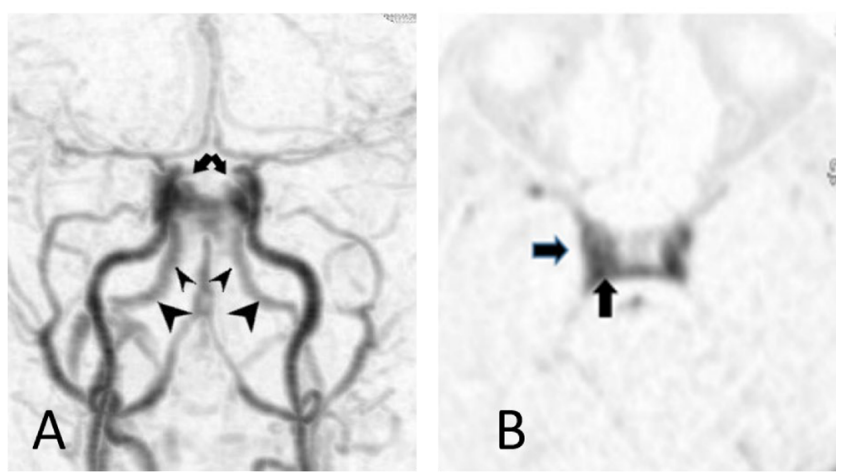

Figure 3. 4D-dynamic contrast-enhanced MR angiography in early arterial phase (A) disclosed a slight asymmetric enhancement of bilateral cavernous sinus (arrows), mainly on the right (arrows), in the subsequent phases (B). This cavernous sinus dural arteriovenous fistula is draining downward through the inferior petrous sinus (A: arrowhead) and not upward through the superior ophthalmic vein, which is present in $9-12 \%$ of all cavernous sinus dural arteriovenous fistulas.
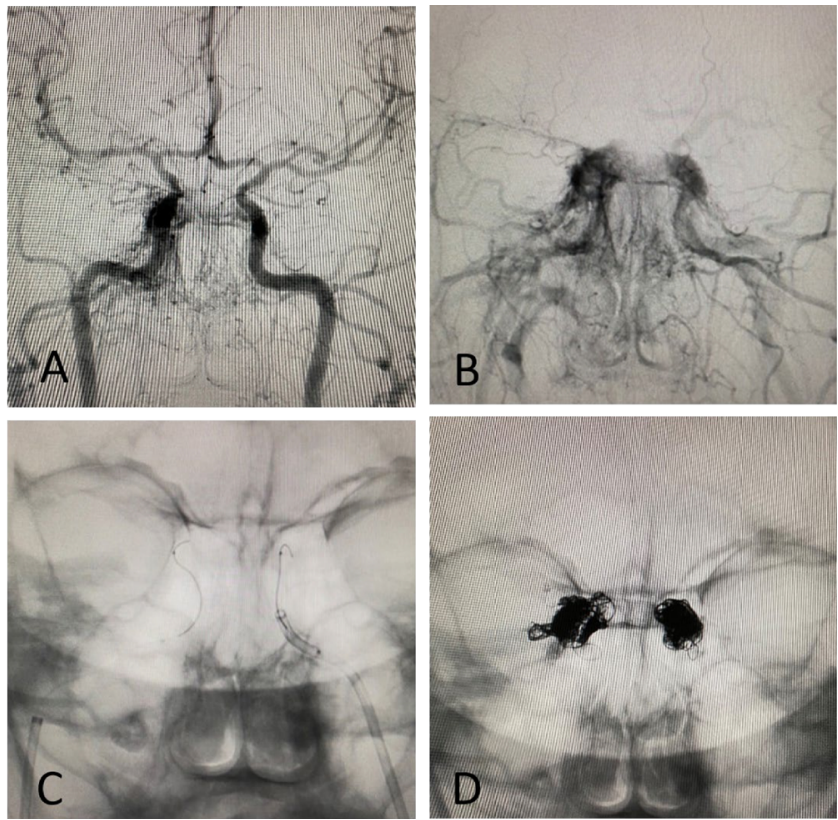

Figure 4. Digital subtraction angiography revealed a bilateral slowflow posterior cavernous sinus dural arteriovenous fistula, mainly on the right ( $\mathrm{A}$ and $\mathrm{B})$. Cavernous sinus dural arteriovenous fistula was successfully treated by venous approach (C). Post-embolization of the cavernous sinus was performed through the inferior petrous sinus, using coils and liquid embolic agents $\left(P i^{\circledR}\right)(D)$.

\section{References}

1. Sakamoto M, Taoka T., Iwasaki S., Nakagawa H., Fukusumi A., Takayama K, et al. Paradoxical parasellar high signals resembling shunt diseases on routine 3D time-of-flight MR angiography of the brain: mechanism for the signals and differential diagnosis from shunt diseases. Magn Reson Imaging. 2004 Nov;22(9):1289-93. https://doi.org/10.1016/j.mri.2004.08.004

2. Guo H, Yin Q, Liu P, Guan N, Huo X, Li Y. Focus on the target: Angiographic features of the fistulous point and prognosis of transvenous embolization of cavernous sinus dural arteriovenous fistula. Interv Neuroradiol. 2018 Apr;24(2):197-205. https://doi. org/10.1177/1591019917751894

3. Stiebel-Kalish H. Cavernous sinus dural arteriovenous malformations Patterns of venous drainage are related to clinical signs and symptoms. Ophthalmology. 2002 Sep;109(9):1685-91. https://doi.org/10.1016/s0161-6420(02)01166-1

4. Acierno MD. Painful oculomotor palsy caused by posteriordraining dural carotid cavernous fistulas. Arch Ophthalmol. 1995 Aug;113(8):1045-9. https://doi.org/10.1001/ archopht.1995.01100080097035

5. Thomas AJ, Chua M, Fusco M, Ogilvy CS, Tubbs RS, Harrigan MR, et al. Proposal of venous drainage-based classification system for carotid cavernous fistulae with validity assessment in a multicenter cohort. Neurosurgery. 2015 Sep;77(3):380-5;discussion 385. https://doi.org/10.1227/ NEU.0000000000000829 